\title{
Increased copy number of syncytin-1 in the trophectoderm is associated with implantation of the blastocyst
}

\author{
Luyan Guo ${ }^{\text {Equal first author, } 1}$, Fang Gu ${ }^{\text {Equal first author, } 2}{ }^{2}$, Yan $\mathrm{Xu}^{2}$, Canquan Zhou ${ }^{\text {Corresp. 2, } 3}$ \\ 1 Department of Obstetrics and Gynecology, Sun Yat-sen University First Affiliated Hospital, Guangzhou, Guangdong, China \\ 2 Reproductive Medical center, Department of Obstetrics and Gynecology, Sun Yat-sen University First Affiliated Hospital, Guangzhou, Guangdong, China \\ 3 Key Laboratory of Reproductive Medicine of Guangdong Province, Guangzhou, Guangdong, China \\ Corresponding Author: Canquan Zhou \\ Email address: zhoucanquan@mail.sysu.edu.cn
}

Background: A key step in embryo implantation is the adhesion to and invasion of the endometrium by the blastocyst trophectoderm. The envelope proteins of HERV-W (human endogenous retrovirus-W), syncytin-1 and syncytin-2, are mainly distributed in the placenta, and play important roles in the development of the placenta. The placenta originates from the trophectoderm of the blastocyst. It is unclear whether the envelope proteins of HERV-W have an effect on the development of the trophectoderm and whether they have any association with the implantation of the blastocyst.

Methods: The whole-genome amplification products of the human blastocyst trophectoderm were used to measure the copy number of syncytin-1 and syncytin-2 using real time qPCR. In addition, clinical data associated with the outcome of pregnancies was collected, and included age, body mass index(BMI), basic follicle stimulating hormone(bFSH), rate of primary infertility and oligo-astheno-teratospermia, the thickness of the endometrium on the day of endometrial transformation, the levels of estrogen and progestin on the transfer day, the days and the morphological scores of the blastocysts. The expression of mRNA and the copy numbers of syncytin- 1 and syncytin- 2 in $\mathrm{H} 1$ stem cells, and in differentiated $\mathrm{H} 1$ cells, induced by BMP4, were measured using real time qPCR.

Results: The relative copy number of syncytin-1 in the pregnant group (median: 424\%, quartile: $232 \%$ $463 \%, p<0.05$ ) was significantly higher than in the non-pregnant group (median: 100\%, quartile: $81 \%$ $163 \%)$. There was a correlation $\left(r_{s}=0.681, p<0.001\right)$ between the copy number of syncytin-1 and blastocyst implantation after embryo transfer. As the stem cells differentiated, the expression of NANOG mRNA decreased, and the expression of caudal type homeobox 2(CDX2) and $\beta$-human chorionic gonadotropin( $\beta$-hCG) mRNAs increased. Compared to the undifferentiated cells, the relative expression of the syncytin-1 mRNA was 1.63 (quartile: 0.59-6.37, $p>0.05$ ), 3.36 (quartile: $0.85-14.80, p>0.05$ ), 10.85 (quartile: 3.39-24.46, $p<0.05$ ) and 67.81 (quartile: 54.07-85.48, $p<0.05$ ) on day $1,3,5$ and 7 , respectively, after the differentiation. The relative expression of syncytin-2 was 5.34 (quartile: 4.50-10.30), 7.90 (quartile: 2.46-14.01), 57.44 (quartile: 38.35-103.87) and 344.76 (quartile: $267.72-440.10)$ on day $1,3,5$ and 7 , respectively, after the differentiation $(p<0.05)$. The copy number of syncytin-1 increased significantly during differentiation.

Conclusion: Preceding the transfer of frozen embryos, the increased copy number of syncytin- 1 in the blastocyst trophectoderm was associated with good outcomes of pregnancies. 
1 Increased copy number of syncytin-1 in the trophectoderm is associated with

2 implantation of the blastocyst

4 Luyan $\mathrm{Guo}^{1 *}$, Fang $\mathrm{Gu}^{2 *}$, Yan Xu², Canquan Zhou²,

5 'Department of Obstetrics and Gynecology, Sun Yat-sen University First Affiliated Hospital, 6 Guangzhou, the People's Republic of China, 510080

7 2Reproductive Medical center, Department of Obstetrics and Gynecology, Sun Yat-sen 8 University First Affiliated Hospital, Guangzhou, the People's Republic of China, 510080

9 'Key Laboratory of Reproductive Medicine of Guangdong Province, Guangzhou, the People's 10 Republic of China, 510080

11 * LuyanGuo and Fang Gu should be considered joint first authors.

12 Corresponding author: Canquan Zhou, zhoucanquan@mail.sysu.edu.cn.

\section{ABSTRACT}

Background: A key step in embryo implantation is the adhesion to and invasion of the endometrium by the blastocyst trophectoderm. The envelope proteins of HERV-W (human endogenous retrovirus-W), syncytin-1 and syncytin-2, are mainly distributed in the placenta, and play important roles in the development of the placenta. The placenta originates from the trophectoderm of the blastocyst. It is unclear whether the envelope proteins of HERV-W have 
an effect on the development of the trophectoderm and whether they have any association with

21 the implantation of the blastocyst.

Methods: The whole-genome amplification products of the human blastocyst trophectoderm were used to measure the copy number of syncytin- 1 and syncytin- 2 using real time qPCR. In addition, clinical data associated with the outcome of pregnancies was collected, and included age, body mass index(BMI), basic follicle stimulating hormone(bFSH), rate of primary infertility and oligo-astheno-teratospermia, the thickness of the endometrium on the day of endometrial transformation, the levels of estrogen and progestin on the transfer day, the days and the morphological scores of the blastocysts. The expression of mRNA and the copy numbers of syncytin-1 and syncytin-2 in $\mathrm{H} 1$ stem cells, and in differentiated $\mathrm{H} 1$ cells, induced by BMP4, were measured using real time qPCR.

Results: The relative copy number of syncytin-1 in the pregnant group (median: $424 \%$, quartile: $232 \%-463 \%, p<0.05$ ) was significantly higher than in the non-pregnant group (median: $100 \%$, quartile: $81 \%-163 \%)$. There was a correlation $\left(r_{s}=0.681, p<0.001\right)$ between the copy number of syncytin-1 and blastocyst implantation after embryo transfer. As the stem cells differentiated, the expression of NANOG mRNA decreased, and the expression of caudal type homeobox 2(CDX2) and $\beta$-human chorionic gonadotropin( $\beta-h C G)$ mRNAs increased. Compared to the undifferentiated cells, the relative expression of the syncytin-1 mRNA was 1.63 (quartile: 0.59 6.37, $p>0.05$ ), 3.36 (quartile: $0.85-14.80, p>0.05$ ), 10.85 (quartile: $3.39-24.46, p<0.05$ ) and 67.81 (quartile: $54.07-85.48, p<0.05$ ) on day $1,3,5$ and 7 , respectively, after the differentiation. 
40 The relative expression of syncytin-2 was 5.34 (quartile: $4.50-10.30$ ), 7.90 (quartile: 2.46-14.01),

4157.44 (quartile: $38.35-103.87$ ) and 344.76 (quartile: $267.72-440.10$ ) on day 1, 3, 5 and 7 , 42 respectively, after the differentiation $(p<0.05)$. The copy number of syncytin-1 increased 43 significantly during differentiation.

Conclusion: Preceding the transfer of frozen embryos, the increased copy number of syncytin1 in the blastocyst trophectoderm was associated with good outcomes of pregnancies.

Keywords: blastocyst implantation, syncytin-1, syncytin-2, trophectoderm

\section{INTRODUCTION}

Failure of the embryo to implant is a crucial limiting factor for early pregnancy and assisted reproduction (Bashiri et al., 2018). The determinants of implantation include the embryo, the receptivity of the endometrium, the fetal-maternal crosstalk, immunity, and other factors (Ashary et al., 2018). A key step during embryo implantation is the adhesion to and invasion of the endometrium by the blastocyst trophectoderm. In the process, various genes and associated molecules take part in modulating the intricate crosstalk between the embryo and the endometrium (Achache \& Revel, 2006). Molecular biological investigation of the blastocyst trophectoderm has the potential of becoming a useful predictive tool for identifying the embryos with the best chance of implantion and successful pregnancy (Ntostis et al., 2019). 
millions of years ago, integrated into the human germ-line DNA(Bannert \& Kurth, 2006). It is estimated that residue gene sequences of HERVs represent up to $8 \%$ of the human genome (Lander, 2011) and the sequences can be vertically transmitted to offspring in a Mendelian fashion(Bannert \& Kurth, 2006). The viral RNA is reverse-transcribed into a double stranded DNA (dsDNA), which is commonly called a provirus and competent for the subsequent integration into the host cell genome. A classical proviral structure includes the main retroviral genes (gag, pro, pol, and env), flanked by the two long terminal repeats(LTRs)(Chen et al., 2019). Most HERVs have accumulated numerous stop codons and frame shift mutations or have undergone recombination between their LTRs, leading to the loss of the entire internal region and leaving only a solo LTR. Most contemporary HERV sequences are unable to encode functional proteins(Stoye, 2001). But some families or family members of HERVs are naturally expressed in particular physiological contexts and display physiological functions. For example, syncytin-1 and syncytin-2 are mainly distributed in the placenta (Soygur \& Sati, 2016). Syncytin1, the envelope protein of HERV-W, mediates the fusion of placental cytotrophoblastic cells to multinucleated syncytiotrophoblast and differentiation of syncytium during placental development(Mi et al., 2000). Syncytin-1 is expressed throughout gestation (Okahara et al., 2004) in syncytiotrophoblast cells(Kudaka et al., 2008; Malassine et al., 2005). It is a target gene of the GCM1 transcription factor, which is itself downstream of cAMP-regulated protein kinase A(Knerr et al., 2005; Yu et al., 2002). The envelope protein strongly induced syncytia formation by interacting with the type D mammalian retrovirus receptor (hASCT2, human sodium-dependent neutral amino acid transporter type 2)(Blond et al., 2000). Its gene harbored 
80 a 5'LTR functional promoter, exhibiting several binding sites for transcriptional regulators

81 involved in the control of proliferation and differentiation(Prudhomme et al., 2004; Frendo et al.,

82 2003). Syncytin-2, the envelope protein of human endogenous retrovirus-FRD (HERV-FRD), is

83 fusogenic (Blaise et al., 2003) and immunosuppressive (Mangeney et al., 2007) in the placenta.

84 It is expressed in villous cytotrophoblast cells, specifically lining the membranes of a subset of

85 cells bordering the syncytiotrophoblast, but not in the syncytiotrophoblast itself(Kudaka et al.,

86 2008; Malassine et al., 2007). Syncytin-2 has an immunosuppressive domain not found in

87 syncytin-1 that may play a role in protecting the fetus from the maternal immune system (Blaise et al., 2003).Previous research on syncytin-1 and syncytin-2 mainly focused on the placenta and rarely involved the early development of the embryo. Recently, Bikem Soygur indicated that syncytin expression is a prerequisite for embryo implantation and placentation. Syncytin-1 is mainly expressed in the trophectoderm cells underlying the inner cell mass of the blastocyst

92 (Soygur \& Moore, 2016). Syncytin might be a marker indicating good implantation potential for early embryos.

The preimplantation genetic diagnoses (PGD) and screening (PGS) are techniques used for determining the genetic status of cells (usually single cell) that have been biopsied from oocytes/zygotes or embryos in assisted reproduction. The number of trophectoderm cells from a blastocyst biopsy is very low. Currently, multiple displacement amplification (MDA) generates abundant assay-ready DNA to perform broad panels of genetic assays through its ability to rapidly amplify genomes from single cell. The residual MDA products from the clinical 
100

101

102

103

104

105

106

measurements provided a chance to analyze the genomes of early embryos in the study. And previous studies found that HERV-W transcripts have the unique capacity to be mobilized by the LINE-1 (L1) retrotransposons. This occurs through the reverse transcription of RNA transcripts originating from preexisting HERV-W proviral insertions, and their subsequent integration into new chromosomal positions (Ostertag \& Kazazian, 2001; Cordaux \& Batzer, 2009; Grandi \& Tramontano, 2017). Consequently, the copy number of the genes from the HERV-W family may be changed by the L1 machinery in a physiological and pathological context. Some researches suggested that multiple sclerosis patients have increased number of HERV-W copies(GarciaMontojo et al., 2013), whereas schizophrenia or bipolar patients appear to have decreased numbers of such copies(Perron et al., 2012). But the changes in the copy number of syncytin-1 and syncytin- 2 were unclear in the genomes of early embryos. The aim of the present study was to evaluate whether the copy numbers of syncytin- 1 and syncytin- 2 have an association with the outcome of the pregnancies of the blastocysts. Because of the damage to embryos by rebiopsies, the expressions of syncytin mRNA cannot be measured in embryos from the pregnant and non-pregnant groups. The in-vitro differentiation model of $\mathrm{H} 1$ stem cell line induced by BMP4 was used to mimic the formation of blastocyst trophectoderm. The copy number and mRNA expressions of syncytin-1 and syncytin-2 were measured before and after differentiation.

\section{MATERIALS AND METHODS}


120 The patient information

121 The patients received PGD or PGS treatments for single gene disorders or chromosome 122 abnormalities at the First Affiliated Hospital of Sun Yat-sen University, from January 2016 to 123 January 2018. After detections, the patients who had transferable embryos, i.e. embryos that 124 did not carry mutated genes and had normal chromosomes, were included in the study. These 125 patients each underwent a single frozen embryo replacement cycle and the outcome of their 126 pregnancy was assessed during follow-up examinations. The inclusion criteria were 127 premenopausal women aged 25-42, whose bFSH was 1-8IU/L and who had more than 10 128 bilateral sinus follicles. None of the patients had a history of hormone or antibiotic treatment for 129 at least three months prior to undergoing the single frozen embryo replacement cycle. Women 130 with endometriosis, polycystic ovarian syndrome, repeated implantation failures, recurrent 131 pregnancy loss, heavy uterine bleeding, potential neoplasms, intrauterine adhesions, scar 132 diverticulum, submucosal uterine fibroids or congenital uterine malformations were excluded 133 from the present study. When a couple lived together and had a normal sex-life, without the use 134 of contraception, if after 1 year the wife did not fall pregnant, the patient was diagnosed as 135 infertile. If the patient had never been pregnant, the patient was diagnosed as having primary 136 infertility. The diagnostic criteria for oligo-astheno-teratospermia was sperm concentration < $13715 \times 10^{6} / \mathrm{ml}$, progressive motility $<32 \%$ and normal morphology $<4 \%$. Our study was initiated after 138 being approved by the Medical Ethics Committee of the First Affiliated Hospital of San Yat-sen 
139 University (\# [2019]41). Waiver of Informed Consent was also approved by the Medical Ethics

140 Committee of the First Affiliated Hospital of San Yat-sen University.

141 The clinical samples

142 The genome-wide amplification products from 6 - 8 trophectoderm cells of the blastocysts were 143 collected. The blastocysts of patients were not rebiopsied. The samples were residual products 144 from clinical tests and one to three blastocysts from each patient were included in the study.

145 The DNA samples were frozen at negative $80^{\circ} \mathrm{C}$.

\section{Clinical data collection}

According to the outcomes of the pregnancies after the embryos were transferred, the two experimental groups were designated the pregnant and non-pregnant groups. The age, BMI, $\mathrm{bFSH}$, the rate of primary infertility and oligo-astheno-teratospermia, the thickness of the endometrium on the day of the endometrial transformation, the levels of estrogen and progestin on the transfer day, the days and morphological scores of the blastocysts, the rate of biochemical pregnancy, the rate of singleton live birth and early miscarriage were collected. The grading by Gardner for scoring the morphology of the blastocysts was used(Gardner \& Schoolcraft, 1999). If the score of a 5-day old blastocyst was $3 A B, 3 B B, 3 B A, 3 A A, 4 A B, 4 B A$, $4 \mathrm{BB}, 4 \mathrm{AA}, 5 \mathrm{AB}, 5 \mathrm{BB}, 5 \mathrm{BA}$ or $5 \mathrm{AA}$, it was classified as a quality embryo. However, when the score of a 6-day old blastocyst was $4 A B, 4 B B, 4 B A, 5 A B, 5 B B, 5 B A$ or $5 A A$, it was also classified as a quality embryo. The number of quality embryos in all of the blastocysts was 
collected. $\beta$-hCG measured in the urine and blood of patients were positive on the $12^{\text {th }}$ day after the transfer. In addition, 3 weeks after transfer, the gestation sac was found to be present in the intrauterine wall using ultrasound. We judged the patient to be pregnant and classified the embryo as being in the pregnant group. Biochemical pregnancy is defined as serum $\beta$-hCG levels>6 IU/L with no gestational sac (determined by ultrasound scan 3 weeks later), or declining serum $\beta$-hCG levels before the ultrasound scan. Early miscarriage was defined as an abortion before 12 weeks of the gestation.

\section{Cell cultures and stem cell differentiation}

The human embryonic stem cell line $\mathrm{H} 1$ was purchased from American Type Culture Collection (ATCC). Prior to differentiation, $\mathrm{H} 1$ stem cell was cultured under feeder-free conditions on Geltrex (Thermo Scientific: A1413302, USA)-coated plates. The culture medium of $\mathrm{H} 1$ cell line was provided by a domestic manufacturer (Cellapy: CA1014500, Beijing, China), supplemented with $100 \mathrm{U} / \mathrm{ml}$ penicillin and $100 \mu \mathrm{g} / \mathrm{ml}$ streptomycin. Cells were passaged with $0.005 \mathrm{M}$ EDTA (Thermo Scientific: 15575020, USA) every 3 to 5 days.

Based on a previously described protocol (Li et al., 2013) with some modifications, H1 stem cell was first cultured for 2 days after the passage. Then, the stem cells were differentiated by using the Knockout DMEM/F12 medium (Thermo Scientific: 12660012, USA) with 20\% serum alternatives (Thermo Scientific: A3181501, USA), 2mM/L L-glutamine, $0.1 \mathrm{mM} / \mathrm{L}$ nonessential amino acid, $10 \mathrm{ng} / \mathrm{mL}$ bone morphogenetic protein-4(BMP4, Thermo Scientific: 
$177 \mathrm{PHC9534,} \mathrm{USA),} 100 \mathrm{U} / \mathrm{ml}$ penicillin and $100 \mu \mathrm{g} / \mathrm{ml}$ streptomycin, for a week. The medium was

178 replaced every day.

179

180

181

182

183

184

185

186

187

188

189

190

191

192

\section{Phalloidin staining}

Cells were fixed using $4 \%$ paraformaldehyde for $30 \mathrm{~min}$ at room temperature and immersed in phosphate buffered saline(PBS) with $0.1 \%$ Triton X-100(Sigma-Aldrich, St. Louis, MO) for 15 min. The cells were stained with actin-tracker green phalloidin (1:50, Beyotime, Beijing, China) at room temperature for 1 hour. Cell nuclei were stained with 4'-6-Diamidino-2-phenylindole (DAPI, Beyotime, Beijing, China) for $10 \mathrm{~min}$ at room temperature. Images were captured using an inverted microscope (DMi8, Leica microsystems, Wetzlar, Germany) and the cross sectional area of cells was computed by ImageJ software.

\section{Quantitative real-time PCR analysis}

The genomic DNA of 6 - 8 trophectoderm cells from each blastocyst was amplified with REPLI-g-Single Cell Kit (150343, Qiagen, Germany) according to the manufacturer's instructions. The amplification products were diluted 100 times with nuclease-free water and then used for detecting the changes in the copy number of the relevant genes. The genomic DNA of the undifferentiated $\mathrm{H} 1$ cells, and the differentiated $\mathrm{H} 1$ cells, were extracted on days 1, 3, 5 and 7 using the universal genomic DNA kit (CW2298S, CWBio, Beijing, China) according to the manufacturer's instructions. The genomic DNA was used for detecting the copy number. The specific primers for the syncytin-1, syncytin-2 and GAPDH used in the quantitative real-time 
196 PCR are listed in Table (1). For syncytin-1, syncytin-2 and GAPDH replication, the PCR cycle

197 was $95^{\circ} \mathrm{C}$ for $10 \mathrm{~min}$, followed by 40 cycles of $95^{\circ} \mathrm{C}$ for $15 \mathrm{~s}, 60^{\circ} \mathrm{C}$ for $30 \mathrm{~s}$, and $72^{\circ} \mathrm{C}$ for $30 \mathrm{~s}$.

198 The copy number measurements of cell line were repeated four times.

199 Quantitative real-time RT-PCR analysis was used to measure the changes in the abundance 200 of NANOG, CDX2, hCG, syncytin-1 and syncytin-2 mRNAs. The total RNA of the 201 undifferentiated $\mathrm{H} 1$ cells and the differentiated $\mathrm{H} 1$ cells on days $1,3,5$, and 7 were extracted 202 using Trizol reagent (B511311-0100, Sangon, Shanghai, China) according to the manufacturer's 203 instructions. Total RNA $(1 \mu \mathrm{g})$ was used in a $20 \mu \mathrm{l}$ first strand cDNA synthesis using a reverse 204 transcription system (R222-01, Vazyme, Nanjing, China). The cDNA (2 $\mu$ l) was used for the 205 qPCR, and the specific primers used for NANOG, CDX2, hCG, syncytin-1, syncytin-2 and 206 GAPDH are listed in Table (2). For quantifying NANOG, CDX2, hCG, syncytin-1, syncytin-2 and $207 \mathrm{GAPDH}$, the qPCR cycle was $95^{\circ} \mathrm{C}$ for $10 \mathrm{~min}$, followed by 40 cycles of $95^{\circ} \mathrm{C}$ for $15 \mathrm{~s}, 60^{\circ} \mathrm{C}$ for $20830 \mathrm{~s}$, and $72^{\circ} \mathrm{C}$ for $30 \mathrm{~s}$. All the experiments were repeated four times.

\section{Statistical Analysis}

210 All analyses were conducted with SPSS 23.0 and GraphPad Prism 6.0 software. The results

211 are presented as the mean \pm SD for normally distributed data or as the median and interquartile

212 range for skewed data. The differences between two groups were analyzed by Student's t test

213 for normally distributed data or by Mann-Whitney $U$ test for skewed data. The differences

214 among more than two groups were analyzed by Kruskal-Wallis $\mathrm{H}$ test. Categorical variables

215 were expressed as percentages and analyzed with the chi-square test. Spearman's Rank 
216 Correlation Coefficient $\left(r_{s}\right)$ was used to analyze the association between the copy number of

217 syncytin-1 and blastocyst implantation. A $p$-value $<0.05$ was considered to be statistically

218 significant.

\section{RESULTS}

\section{The clinical data of patients}

Thirty-two embryos in the pregnant group and 29 embryos in the non-pregnant group were enrolled in the study. The woman in the two groups did not differ significantly in terms of their age, BMI, basic FSH, the incidence of primary infertility and oligo-astheno-teratospermia, the ratio of good blastocysts, the thickness of the endometrium on the conversion day, and the level of estrogen and progestin on the day of embryo transfer. These factors affecting the outcome of the pregnancy were balanced between the two groups. In addition, the rate of biochemical pregnancy, singleton live birth and early miscarriage in the pregnant group were also collected.

228 The clinical characteristics of the patients in the study are listed in Table (3).

The changes in the relative copy number of syncytin-1 and syncytin-2 between the pregnant and non-pregnant groups

231 The median of the copy number of syncytin-1 or syncytin-2 in the non-pregnant group was used as the references, respectively. The relative copy number of syncytin- 1 in the pregnant group (median: $424 \%$, quartile: $232 \%-463 \%$ ) was statistically significantly higher $(p<0.05$, than in the non-pregnant group (median: 100\%, quartile: $81 \%$ - 163\%) (Figure 1-A). However, 
235 the difference in the relative copy number of syncytin-2 between the pregnant group (median:

$236129 \%$, quartile: $75 \%$ - 201\%) and non-pregnant group (median: 100\%, quartile: 65\% - 142\%)

237 was not statistically significant $(p>0.05)$ (Figure 1-B).

238 The copy number of syncytin-1 in the blastocyst trophectoderm was significantly 239 associated with the outcomes of the pregnancy

240 Based on the balanced basic factors affecting the outcomes of the pregnancy between the

241 pregnant and non-pregnant groups, the relation of the copy number of syncytin-1 and 242 pregnancy outcome was analyzed using Spearman's Rank Correlation Coefficient $\left(\mathrm{r}_{\mathrm{s}}\right)$. The copy 243 number of syncytin-1 was significantly correlated $\left(r_{s}=0.681, p<0.001\right)$ with the outcomes of 244 the pregnancies. The implantation of the blastocyst is the first step for a successful pregnancy, 245 the increased copy number of syncytin-1 in the blastocyst trophectoderm was significantly 246 associated with blastocyst implantation (Figure 1-C).

BMP4 induced differentiation of $\mathrm{H} 1$ stem cell line into trophoblast cells

The differentiation model of $\mathrm{H} 1$ stem cell line induced by BMP4 was used to mimic the formation of blastocyst trophectoderm. Before differentiation, the cytoplasm in the undifferentiated cells was little and the cells gathered together like a clone (Fig 2). The average cross sectional area of undifferentiated $\mathrm{H} 1$ cells was $147.18 \pm 34.78 \mu \mathrm{m}^{2}$ (Figure $3 \mathrm{~A}$, B and C).

252 After differentiation, the morphology of $\mathrm{H} 1$ cell line changed significantly. The cytoplasm increased and the cell had increased protrusions and branches (Figure 2). The average cross 
254 sectional area of differentiated $\mathrm{H} 1$ cells was $805.03 \pm 204.68 \mu \mathrm{m} 2$ (Figure 3D, E and F), which

255 was larger than the area of undifferentiated H1 cells significantly (Figure $3 G, p<0.001$ ). The

256 changes of NANOG, CDX2 and $\beta$-hCG mRNA were measured before and after differentiation of

$257 \mathrm{H} 1$ cell line. The mRNA expression of undifferentiated cells was used as the reference. Embryo

258 stem cells from the inner cell mass of the blastocyst have the potential of self-regeneration and

259 multi-directional differentiation(Edwards, 2004). NANOG is a pivotal transcription factor

260 maintaining the above potential of the stem cells. It is specifically expressed in undifferentiated

261 stem cells and is not expressed in mature cells (Chambers et al., 2003). Compared to the

262 undifferentiated cells, the relative expression medians of NANOG mRNA were 0.77 (quartile:

0.59-0.82, $p>0.05$ ), 0.53 (quartile: $0.40-0.87, p>0.05$ ), 0.11 (quartile: $0.05-0.20, p<0.05$ ) and

0.02 (quartile: $0.01-0.04, p<0.05$ ) on day $1,3,5$ and 7 , respectively, after the differentiation

(Fig. 4-A). These showed that the pluripotency of $\mathrm{H} 1$ cell line had decreased. CDX2 plays a role

from the blastocyst stage, by determining the formation of the trophectoderm (Niwa et al., 2005).

As the differentiation proceeded, the relative expression medians of CDX2 mRNA were 1.44

268 (quartile: 1.37- 1.73), 1.96 (quartile: 1.70- 2.31), 2.94 (quartile: 2.53-4.27) and 1.88 (quartile:

1.59-2.04) on days $1,3,5$ and 7 , respectively, after the differentiation (Fig 4-B, $p<0.05)$ ).

CDX2 is a marker of early trophoblast cells, the increased expression of which indicated that $\mathrm{H} 1$

cell line had differentiated into early trophoblast cells. The relative expression of $\beta$-hCG mRNA

was transformed by the square root. Compared to the undifferentiated cells, the medians of

square root of $\beta$-hCG mRNA expression were 1.37 (quartile: 0.93-1.94, $p>0.05$ ), 1.60 (quartile:

274 1.08-2.43, $p>0.05$ ), 3.84 (quartile: 2.41-5.27, $p<0.05$ ) and 22.19 (quartile: 17.31-41.99, $p<$ 
2750.05 ) on day $1,3,5$ and 7 , respectively, after the differentiation (Fig 4-C). $\beta$-hCG is a marker of

276 mature trophoblasts, the increased expression of which indicated that $\mathrm{H} 1$ cell line had

277 differentiated into trophoblast cells. The results suggested that $\mathrm{H} 1$ cell line was successfully

278 induced to differentiate into trophoblast cells by BMP4.

279 The expression of syncytin-1 and syncytin-2 mRNAs increased as H1 cell line

280 differentiated into trophoblast cells.

281 The mRNA expression of the undifferentiated cells was used as the reference. Compared to

282 the undifferentiated cells, the relative expression medians of syncytin-1 mRNA were 1.63

283 (quartile: $0.59-6.37, p>0.05$ ), 3.36 (quartile: $0.85-14.80, p>0.05$ ), 10.85 (quartile: 3.39-24.46,

$284 p<0.05$ ) and 67.81 (quartile: $54.07-85.48, p<0.05$ ) on day $1,3,5$ and 7 , respectively, after the

285 differentiation (Fig 5-A). The relative expression medians of syncytin-2 were 5.34 (quartile: 4.50-

286 10.30), 7.90 (quartile: 2.46-14.01), 57.44 (quartile: 38.35-103.87) and 344.76 (quartile: 267.72-

$287440.10)$ on day $1,3,5$ and 7 , respectively, after the differentiation $(p<0.05$, Fig 5-B). As the

288 differentiation proceeded, it was found that the expression of syncytin-1 and syncytin-2 mRNAs

289 increased. The model of stem cell differentiation was used to simulate the differentiation of the

290 trophectoderm from the blastocyst. The increased mRNA expression indicated that the syncytin-

2911 and syncytin-2 may play a role in the development of early trophoblasts.

292 The copy numbers of syncytin-1 increased as H1 cell line differentiated into trophoblast

293 cells. 
294 The copy number of undifferentiated cells was used as the reference. Compared to the 295 undifferentiated cells, the relative copy numbers of syncytin-1 were 1.55(quartile: 1.51-1.71), 296 1.53(quartile: 1.42-1.61), 1.55(quartile: 1.39-1.79) and 1.82(quartile: 1.50-2.01) on day 1, 3, 5 297 and 7, respectively, after differentiation ( $p<0.05$, Fig $5-C)$. The relative copy numbers of 298 syncytin-2 were 1.13(quartile: 0.93-1.23), 1.12(quartile: 1.00-1.17), 1.16(quartile: 1.11-1.54) and 299 1.18(quartile: 1.07-1.33) on day 1, 3, 5 and 7, respectively, after the differentiation $(p>0.05$, Fig 300 5-D). During the differentiation, the copy numbers of syncytin-1 increased significantly, but the copy number of syncytin-2 did not have significant change statistically.

\section{DISCUSSION}

Improvements have been made in human assisted reproduction techniques (ART) over the past decades, but embryo implantation remains the rate-limiting step for the success of ART(Spinella et al., 2018). Although the PGD and PGS are used for screening potentially transferable embryos, i.e. embryos that do not carry any mutated genes and have normal chromosomes, despite this, not all of the transferable embryos implant successfully (Sciorio et al., 2020). Improving the implantation rate of embryos is an urgent issue for assisted reproduction. Previously, the clinicians mainly used the morphological grade of the embryos to prioritize the transferable ones (Ziebe et al., 1997). But high grade embryos, determined using

312 the morphological grade, may not have good implantation potential. At present, researchers are 
313 putting more attention into determining how to identify the best embryos that have a high

314 potential for implantation and successful pregnancy(Sigalos et al., 2016).

315 The attachment and implantation of the human blastocyst occurs via the polar TE near the

316 inner cell mass(ICM)(Gamage et al., 2016). Following implantation, human TE cells begin to

317 differentiate into primitive mononuclear cytotrophoblast (CT) and primitive multinucleated

318 syncytiotrophoblast (ST)(Boss et al., 2018). It is known that syncytin-1 mediates the fusion of

319 placental cytotrophoblastic cells to multinucleated syncytiotrophoblast and differentiation of

320 syncytium during placental development (Mi et al., 2000), but its role in early embryo

321 development remains unclear. A previous research showed that a number of HERVs were

322 transcribed when the genome is first activated in around the 8-cell stage(Grow et al., 2015).

323 Bikem s. et al. also showed that syncytin-1 protein expression was mainly in trophectoderm

324 cells of human preimplantation blastocysts and it might have a function in embryo adhesion and

325 attachment to endometrium. The HERV-W family is a multicopy, retrotransposably active family

326 (Belshaw et al., 2005), with dozens of env-related regions in the human genome (Voisset et al.,

327 2000). The copy number of the genes from the HERV-W family may be changed by the L1

328 machinery(Ostertag \& Kazazian, 2001; Cordaux \& Batzer, 2009; Grandi \& Tramontano, 2017).

329 In the present study, we found that compared with the non-pregnant group, the copy number of

330 syncytin-1 from the blastocyst trophectoderm was significantly higher in the pregnant group. But

331 the copy number of syncytin-2 in the pregnant group was similar to the copy number in the non-

332 pregnant group. The regulatory mechanism of syncytin-2 expression might be different from 
syncytin-1. It did not increase the transcripts by changing the gene copy number at the DNA

level. The transcription rate of the syncytin gene is also regulated by the promoter region in and

close to the $5^{\prime}$ long terminal repeat region ( $\left.5^{\prime} L T R\right)$ of the provirus(Yu et al., 2002). On the basis

that the clinical factors affecting the outcomes of pregnancy were balanced between the two

groups, we assessed the association between the copy number of syncytin-1 and the outcome

of pregnancy using Spearman's Rank Correlation Coefficient. It was found that the copy number

of syncytin-1 from the blastocyst trophectoderm was positively associated with pregnancy. This

indicated that embryos with a higher copy number of syncytin-1 might have better

developmental potential. The rebiopsy of trophectoderms of blastocysts will decrease the rate of

survival and implantation of embryos of patients that have been given treatments of PGD or

PGS(Bradley et al., 2017). To identify the association of syncytin copy number and gene

expression, the model of stem cell differentiation was used. As the differentiation proceeded, it

was found that the expression and copy number of syncytin-1 both increased. The expression of

syncytin-2 mRNA increased, but its copy number did not change significantly at the DNA level.

The increased copy number of syncytin-1 may provide more transcription templates to promote gene expression. The expression of syncytin-2 might be regulated by other mechanisms. To determine the regulatory mechanisms, more basic experiments are needed. The copy number changes were detected by using real time quantitative PCR, a method that has been used by many other researchers (Providenti et al., 2006; Zhao et al., 2015; Paakkanen et al., 2012). The primers in our experiment could specifically amplify the syncytin-1 and syncytin-2 genes in the

genome (Table 1). The different quantity of primary templates from the biopsied blastocyst 
354 trophectoderm was corrected by using the synchronous measurement of GAPDH, as an internal

355 reference gene. The measurement was suitable for the patients that received treatments of

356 PGD and PGS as the residual amplification products from the biopsied trophectoderm could be

357 reused. There are some differences in the gene expression of polar and mural trophectoderm

358 (Petropoulos et al., 2016). The biopsy of blastocysts collected the mural trophectoderm. We

359 analyzed the genome DNA of trophectoderm, which avoided the differences of gene expression

360 between the polar and mural trophectoderm.

361 In the present study, there were still some limitations. The sample size of embryos was small

362 and the embryos were all from patients that received PGD or PGS treatments for single gene

363 disorders or chromosome abnormalities. Some patients suffered from primary infertility or oligo-

364 astheno-terato-spermia. These factors will have some effects on the embryos, but they were

365 balanced between the pregnant and non-pregnant groups. A prospective study on the copy

366 number of syncytin-1 and pregnancy outcome among patients who have none of the above

367 diseases and agree to biopsies of their embryos, would make a contribution to the conclusions

368 of the present study.

370 CONCLUSIONS

371 The increased copy number of syncytin-1 was associated with good outcomes of pregnancies

372 after the transfer of frozen embryos. The expressions of syncytin-1 and syncytin-2 mRNA

373 increased during the process of differentiation from stem cells into trophoblasts induced by 
374 BMP4. The DNA copy number of syncytin-1 may be a potential marker in detecting embryos

375 with high potential for implantation. The present study provides a new method for accurate

376 selection of embryos to be transferred. The method is especially suitable for patients that have

377 received PGD or PGS treatments. The clinicians could use the morphological grade of the

378 embryos and copy number of syncytin-1 to prioritize the transferable embryos. This new method

379 is expected to improve the success of ART.

References

Achache H., and Revel A. 2006. Endometrial receptivity markers, the journey to successful embryo implantation HUMAN REPRODUCTION UPDATE 12:731-746.

DOI 10.1093/humupd/dml004 
395

396

Ashary N., Tiwar, A., and Modi D. 2018. Embryo Implantation: War in Times of Love. ENDOCRINOLOGY 159:1188-1198. DOI 10.1210/en.2017-03082

Bannert N., and Kurth R. 2006. The evolutionary dynamics of human endogenous retroviral families. Annu Rev Genomics Hum Genet 7:149-173. DOI 10.1146/ annurev.genom.7.080505.115700

Bashiri A., Halper K.I., and Orvieto R. 2018. Recurrent Implantation Failure-update overview on etiology, diagnosis, treatment and future directions. Reprod Biol Endocrinol 16:121. DOI $10.1186 / \mathrm{s} 12958-018-0414-2$

Belshaw R., Katzourakis A., Paces J., Burt A., and Triste, M. 2005. High copy number in human endogenous retrovirus families is associated with copying mechanisms in addition to reinfection. MOLECULAR BIOLOGY AND EVOLUTION 22:814-817. DOI 10.1093/molbev/msi088

Blaise S., de Parseval N., Benit L., and Heidmann T. 2003. Genomewide screening for fusogenic human endogenous retrovirus envelopes identifies syncytin 2, a gene conserved on primate evolution. Proc Natl Acad Sci $U$ S A 100:13013-13018. DOI 10.1073/pnas. 2132646100

Blond J.L., Lavillett, D., Cheynet V., Bouton O., Oriol G., Chapel-Fernandes S., Mandrand B., Mallet F., and Cosset F.L. 2000. An envelope glycoprotein of the human endogenous retrovirus HERV-W is expressed in the human placenta and fuses cells expressing the type D mammalian retrovirus receptor. JOURNAL OF VIROLOGY 74:3321-3329. DOI 10.1128/jvi.74.7.3321-3329.2000

Bos, A.L., Chamley L.W., and James J.L. 2018. Placental formation in early pregnancy: how is the centre of the placenta made? HUMAN REPRODUCTION UPDATE 24:750-760. DOI 10.1093/humupd/dmy030 
419 Bradley C.K., Livingstone M., Traversa M.V., and McArthur S.J. 2017. Impact of multiple 420 blastocyst biopsy and vitrification-warming procedures on pregnancy outcomes. FERTILITY AND STERILITY 108:999-1006. DOI 10.1016/j.fertnstert. 2017.09.013

422

423

424

425

426

427

Chambers I., Colby D., Robertson M., Nichols J., Lee S., Tweedi, S., and Smith A. 2003. Functional expression cloning of Nanog, a pluripotency sustaining factor in embryonic stem cells. CELL 113:643-655. DOI 10.1016/s0092-8674(03)00392-1

Chen J., Foroozesh M., and Qin Z. 2019. Transactivation of human endogenous retroviruses by tumor viruses and their functions in virus-associated malignancies. Oncogenesis 8:6. DOI 10.1038/s41389-018-0114-y

Cordaux R., and Batzer M.A. 2009. The impact of retrotransposons on human genome evolution. NATURE REVIEWS GENETICS DOI 10:691-703.10.1038 /nrg2640

Edwards R.G. 2004. Stem cells today: A. Origin and potential of embryo stem cells. REPRODUCTIVE BIOMEDICINE ONLINE 8:275-306. DOI 10.1016/s1472-6483(10)60910-8

Frendo J.L., Olivier D., Cheynet V., Blond J.L., Bouton O., Vidaud M., Rabreau M., Evain-Brion D., and Mallet F. 2003. Direct involvement of HERV-W Env glycoprotein in human trophoblast cell fusion and differentiation. MOLECULAR AND CELLULAR BIOLOGY 23:3566-3574. DOI 10.1128/mcb.23.10.3566-3574.2003

Gamage T.K., Chamley L.W., and James J.L. 2016. Stem cell insights into human trophoblast lineage differentiation. HUMAN REPRODUCTION UPDATE 23:77-103. DOI 10.1093/humupd/dmw026

Garcia-Montojo M., Dominguez-Moz, M., Arias-Leal A., Garcia-Martinez A., De Las H.V., Casanova I., Faucard R., Gehi, N., Madeir, A., Arroyo R., Curtin F., Alvarez-Lafuente R., and Perron H. 2013. The DNA copy number of human endogenous retrovirus-W (MSRV-type) is increased in multiple sclerosis patients and is influenced by gender and disease severity. 
443

444

445

446

447

448

449

450

451

452

453

454

455

456

457

458

459

460

461

462

463

464

465

466

PLoS One 8:e53623. DOI 10.1371/journal.pone.0053623

Gardner D.K., and Schoolcraft W.B. 1999. Culture and transfer of human blastocysts. Curr Opin Obstet Gynecol 11:307-311. DOI 10.1097/00001703-199906000-00013

Grandi N., and Tramontano E. 2017. Type W Human Endogenous Retrovirus (HERV-W) Integrations and Their Mobilization by L1 Machinery: Contribution to the Human Transcriptome and Impact on the Host Physiopathology. Viruses 9. DOI 10.3390/v9070162

Grow E.J., Flynn R.A., Chavez S.L., Bayless N.L., Wossidlo M., Wesche D.J., Martin L., Ware C.B., Blish C.A., Chang H.Y., Pera R.A., and Wysocka J. 2015. Intrinsic retroviral reactivation in human preimplantation embryos and pluripotent cells. NATURE 522:221-225. DOI 10.1038/nature14308

Kner I., Schubert S.W., Wich C., Amann K., Aigner T., Vogler T., Jung R., Dotsch J., Rascher W., and Hashemolhossein, S. 2005. Stimulation of GCMa and syncytin via cAMP mediated PKA signaling in human trophoblastic cells under normoxic and hypoxic conditions. FEBS LETTERS 579:3991-3998. DOI 10.1016/j.febslet.2005.06.029

Kudaka W., Oda T., Jinno Y., Yoshim, N., and Aoki Y. 2008. Cellular localization of placentaspecific human endogenous retrovirus (HERV) transcripts and their possible implication in $\begin{array}{lll}\text { pregnancy-induced } \quad \text { 29:282-289. Dypertension. } & \text { DOI }\end{array}$ 10.1016/j.placenta.2007.11.009

Lander E.S. 2011. Initial impact of the sequencing of the human genome. NATURE 470:187197. DOI 10.1038/nature09792

Li Y., Moretto-Zita M., Soncin F., Wakeland A., Wolfe L., Leon-Garcia S., Pandian R., Pizzo D., Cui L., Nazor K., Loring J.F., Crum C.P., Laurent L.C., and Parast M.M. 2013. BMP4directed trophoblast differentiation of human embryonic stem cells is mediated through a DeltaNp63+ cytotrophoblast stem cell state. DEVELOPMENT 140:3965-3976. DOI 
467

468

469

470

471

472

473

474

475

476

477

478

479

480

481

482

483

484

485

486

487

488

489

490

10.1242/dev.092155

Malassine A., Blaise S., Handschuh K., Lalucque H., Dupressoir A., Evain-Brion D., and Heidmann T. 2007. Expression of the fusogenic HERV-FRD Env glycoprotein (syncytin 2) in human placenta is restricted to villous cytotrophoblastic cells. PLACENTA 28:185-191. DOI 10.1016/j.placenta.2006.03.001

Malassine A., Handschuh K., Tsatsaris V., Gerbaud P., Cheynet V., Oriol G., Mallet F., and Evain-Brion D. 2005. Expression of HERV-W Env glycoprotein (syncytin) in the extravillous trophoblast of first trimester human placenta. PLACENTA 26:556-562. DOI 10.1016/j.placenta.2004.09.002

Mangeney M., Renard M., Schlecht-Louf G., Bouallaga I., Heidmann O., Letzelter C., Richaud A., Ducos B., and Heidmann T. 2007. Placental syncytins: Genetic disjunction between the fusogenic and immunosuppressive activity of retroviral envelope proteins. Proc Natl Acad Sci U S A 104:20534-20539. DOI 10.1073/pnas.0707873105

M S., Lee X., Li X., Veldman G.M., Finnerty H., Racie L., LaVallie E., Tang X.Y., Edouard P., Howes S., Keith J.J., and McCoy J.M. 2000. Syncytin is a captive retroviral envelope protein involved in human placental morphogenesis. NATURE 403:785-789. DOI 10.1038/35001608

Niwa H., Toyooka Y., Shimosato D., Strumpf D., Takahashi K., Yagi R., and Rossant J. 2005. Interaction between Oct3/4 and Cdx2 determines trophectoderm differentiation. CELL 123:917-929. DOI 10.1016/j.cell.2005.08.040

Ntostis P., Kokkali G., Iles D., Huntriss J., Tzetis M., Picton H., Pantos K., and Miller D. 2019. Can trophectoderm RNA analysis predict human blastocyst competency? Systems Biology in Reproductive Medicine 65:312-325.DOI 10.1080/19396368. 2019.1625085

Okahara G., Matsubara S., Oda T., Sugimoto J., Jinno Y., and Kanaya F. 2004. Expression analyses of human endogenous retroviruses (HERVs): tissue-specific and developmental 
491

492

493

494

495

496

497

498

499

stage-dependent expression of HERVs. GENOMICS 84:982-990. DOI 10.1016/j.ygeno.2004.09.004

Ostertag E.M., and Kazazian H.J. 2001. Biology of mammalian L1 retrotransposons. Annual Review of Genetics 35:501-538.DOI 10.1146/annurev.genet.35.102401. 091032

Paakkanen R., Vauhkonen H., Eronen K.T., Jarvinen A., Seppanen M., and Lokk, M.L. 2012. Copy number analysis of complement C4A, C4B and C4A silencing mutation by real-time quantitative polymerase chain reaction. PLoS One 7:e38813.DOI 10.1371/journal.pone.0038813

Perron H., Hamdani N., Faucard R., Lajnef M., Jamain S., Daban-Huard C., Sarrazin S., LeGuen E., Houenou J., Delavest M., Moins-Teisserenc H., Bengoufa D., Yolken R., Madeira A., Garcia-Montojo M., Gehin N., Burgelin I., Ollagnier G., Bernard C., Dumaine A., Henrion A., Gombert A., Le Dudal K., Charron D., Krishnamoorthy R., Tamouza R., and Leboyer M. 2012. Molecular characteristics of Human Endogenous Retrovirus type-W in schizophrenia and bipolar disorder. Trans/ Psychiatry 2:e201. DOI 10.1038/tp.2012.125

Petropoulos S., Edsgard D., Reinius B., Deng Q., Panula S.P., Codeluppi S., Plaza R.A., Linnarsson S., Sandberg R., and Lanner F. 2016. Single-Cell RNA-Seq Reveals Lineage and X Chromosome Dynamics in Human Preimplantation Embryos. CELL 165:1012-1026. DOI 10.1016/j.cell.2016.03.023

Providenti M.A., O'Brien J.M., Ewing R.J., Paterson E.S., and Smith M.L. 2006. The copynumber of plasmids and other genetic elements can be determined by SYBR-Green-based quantitative real-time PCR. J Microbiol Methods 65:476-487. DOI 10.1016/j.mimet.2005.09.007

Prudhomme S., Oriol G., and Mallet F. 2004. A retroviral promoter and a cellular enhancer define a bipartite element which controls env ERVWE1 placental expression. JOURNAL OF VIROLOGY 78:12157-12168.DOI 10.1128/JVI.78.22. 12157-12168.2004 
516 Sciorio R., Tramontano L., and Catt J. 2020. Preimplantation genetic diagnosis (PGD) and 517 genetic testing for aneuploidy (PGT-A): status and future challenges. GYNECOLOGICAL

Soygur B., and Moore H. 2016. Expression of Syncytin 1 (HERV-W), in the preimplantation human blastocyst, embryonic stem cells and trophoblast cells derived in vitro. HUMAN REPRODUCTION 31:1455-1461. DOI 10.1093/humrep/ dew097

Soygur B., and Sati L. 2016. The role of syncytins in human reproduction and reproductive organ cancers. REPRODUCTION 152:R167-R178. DOI 10.1530/ REP-16-0031

Spinella F., Fiorentino F., Biricik A., Bono S., Ruberti A., Cotroneo E., Baldi M., Cursio E., Minasi M.G., and Greco E. 2018. Extent of chromosomal mosaicism influences the clinical outcome of in vitro fertilization treatments. FERTILITY AND STERILITY 109:77-83. DOI 10.1016/j.fertnstert.2017.09.025

Stoye J.P. 2001. Endogenous retroviruses: still active after all these years? CURRENT BIOLOGY 11:R914-R916.DOI 10.1016/s0960-9822(01)00553-x

Voisset C., Bouton O., Bedin F., Duret L., Mandrand B., Mallet F., and Paranhos-Baccala G. 2000. Chromosomal distribution and coding capacity of the human endogenous retrovirus HERV-W family. AIDS Res Hum Retroviruses 16:731-740. DOI 10.1089/088922200308738

Yu C., Shen K., Lin M., Chen P., Lin C., Chang G.D., and Chen H. 2002. GCMa regulates the syncytin-mediated trophoblastic fusion. JOURNAL OF BIOLOGICAL CHEMISTRY 277:50062-50068. DOI 10.1074/jbc.M209316200

Zhao Q., Xie S., Sun Y., Chen Y., Gao J., Li H., Wang X., Syed S.F., Liu B., Wang L., Zhang G., 
540 and Zhou E.M. 2015. Development and evaluation of a SYBR Green real-time RT-PCR 541 assay for detection of avian hepatitis E virus. BMC Veterinary Research 11:195. DOI $542 \quad 10.1186 / s 12917-015-0507-5$

543 Ziebe S., Petersen K., Lindenberg S., Andersen A.G., Gabrielsen A., and Andersen A.N. 1997. 544 Embryo morphology or cleavage stage: how to select the best embryos for transfer after in545 vitro fertilization. HUMAN REPRODUCTION 12:1545-1549. DOI 10.1093/humrep/12.7.1545 
Figure 1

The relative copy number of syncytin-1 in the blastocyst trophectoderm was significantly associated with blastocyst implantation

A: The relative copy number of syncytin-1 between the non-pregnant and pregnant groups;

B: The relative copy number of syncytin-2 between the non-pregnant and pregnant groups;

C: Spearman Rank Correlation between the copy number of syncytin-1 and the outcomes of the pregnancies after embryo transfer
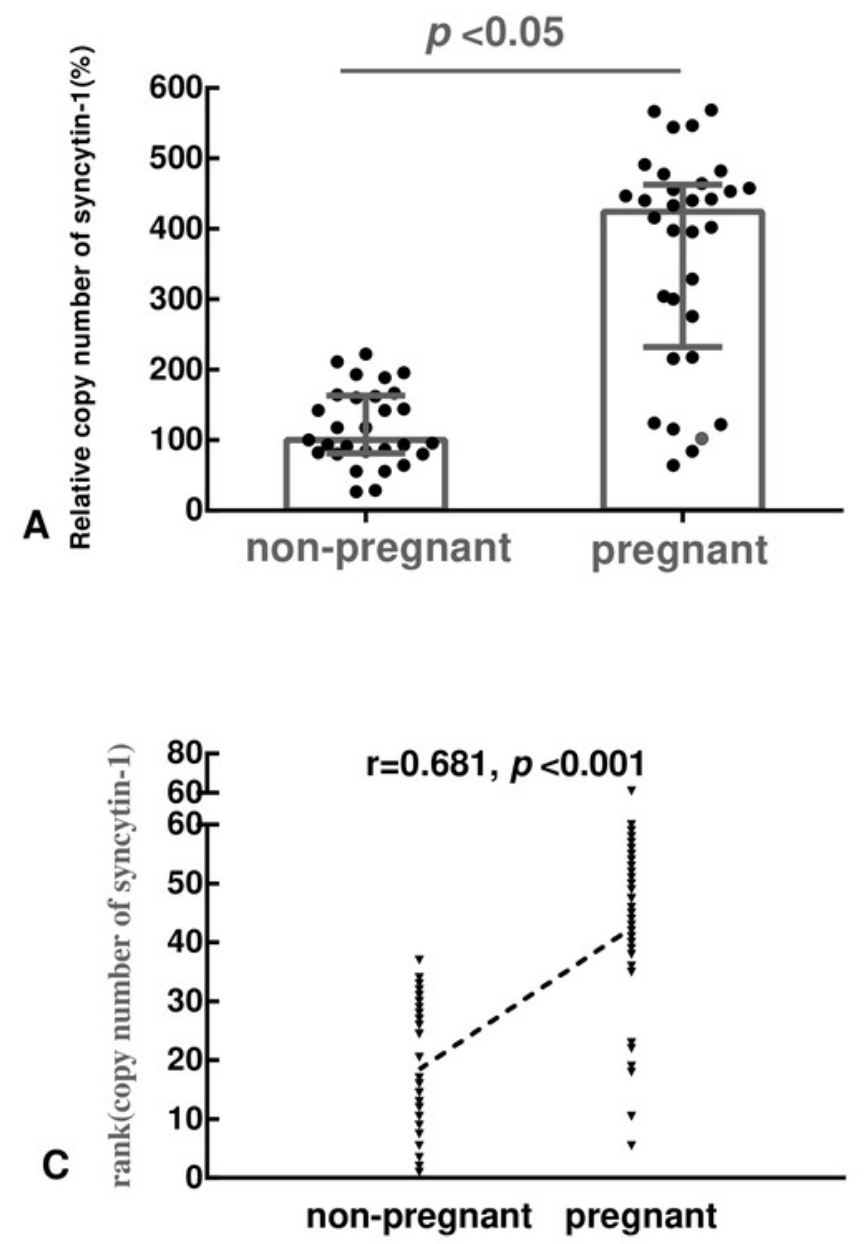

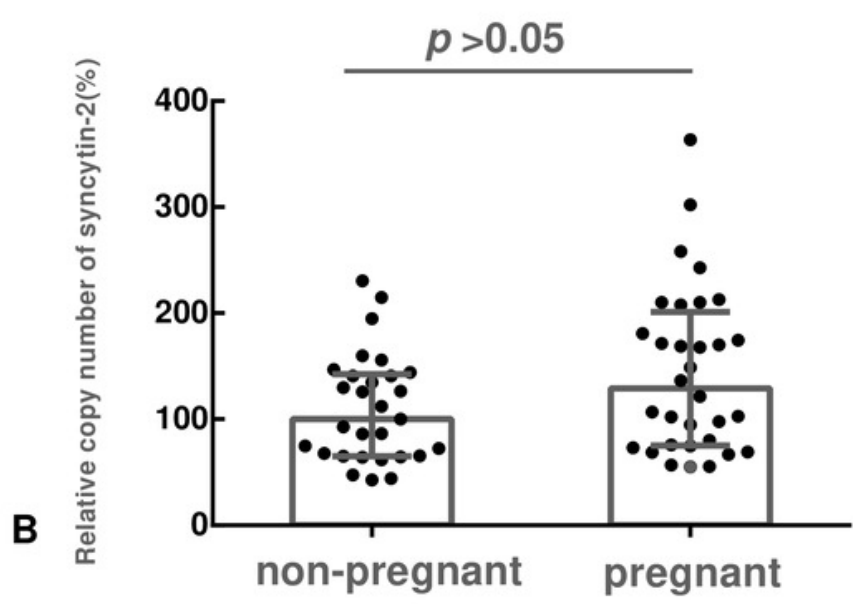


Figure 2

The morphological characteristics of the undifferentiated and the differentiated $\mathrm{H} 1$ cells.

A: undifferentiated $\mathrm{H} 1$ cells; $\mathrm{B}$ : differentiated cells induced by BMP4 for 1 day; C:

differentiated cells induced by BMP4 for 3 days; D: differentiated cells induced by BMP4 for 5 days; E: differentiated cells induced by BMP4 for 7 days 


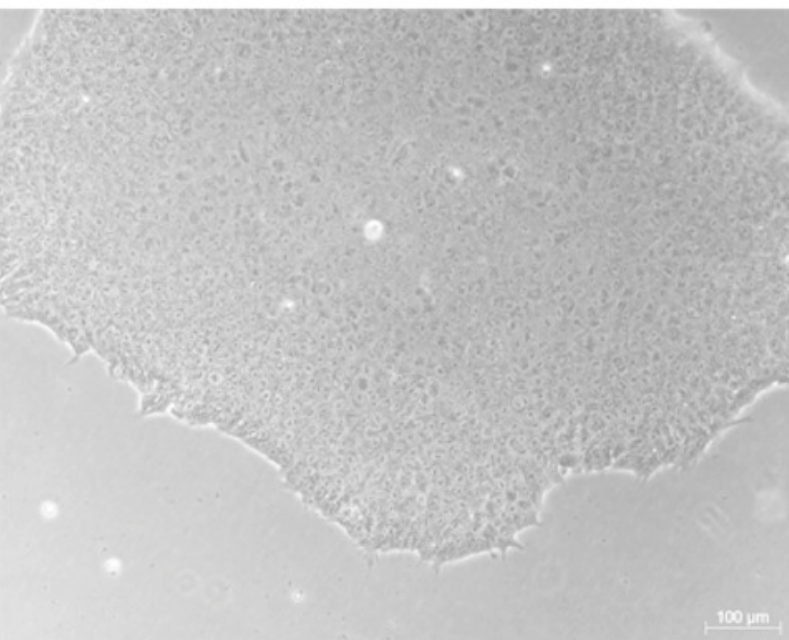

A

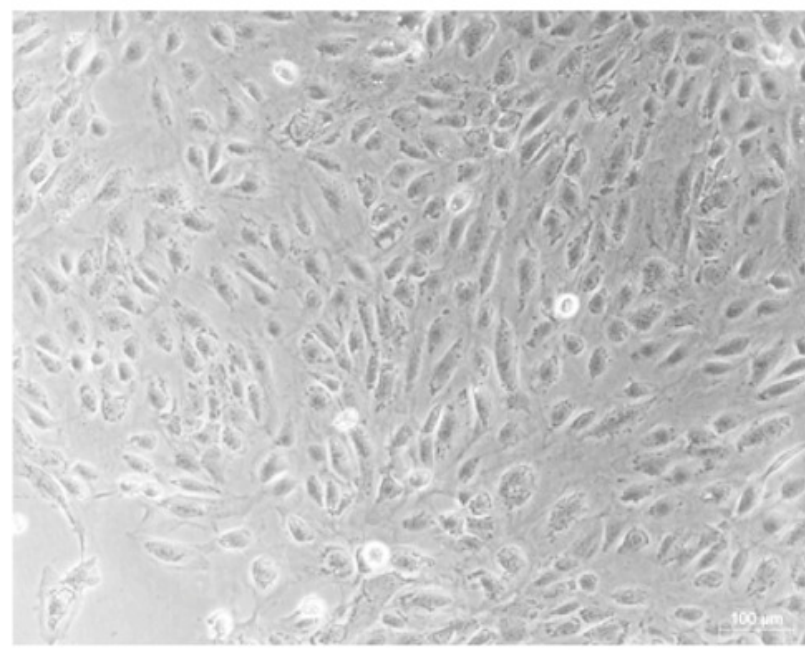

C

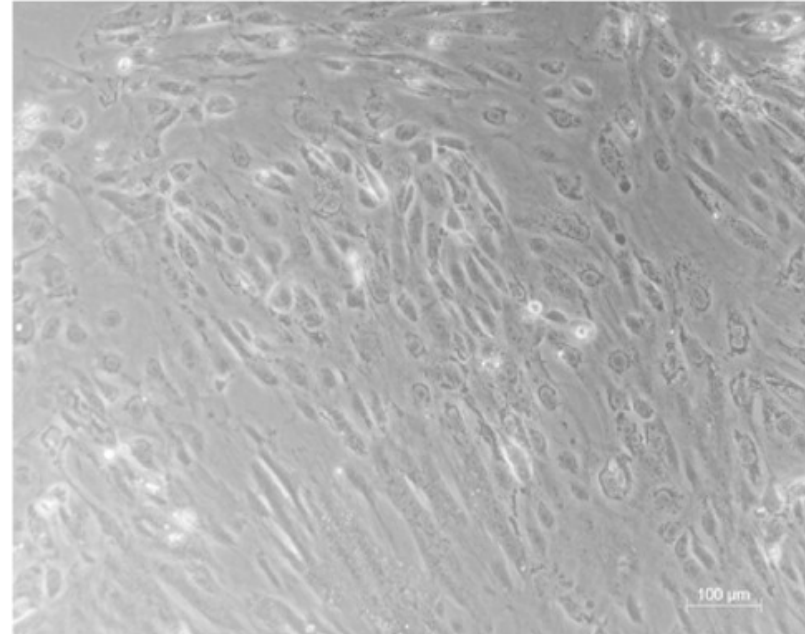

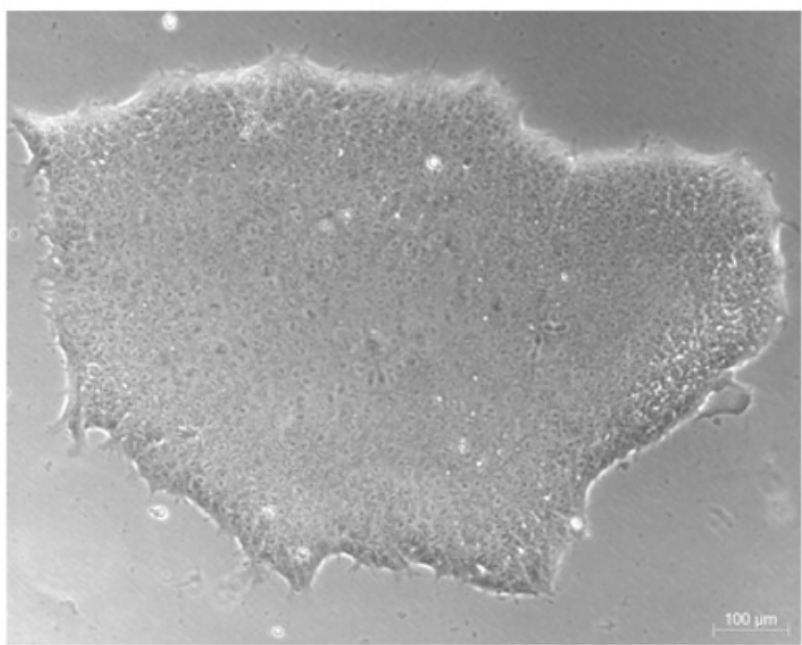

B

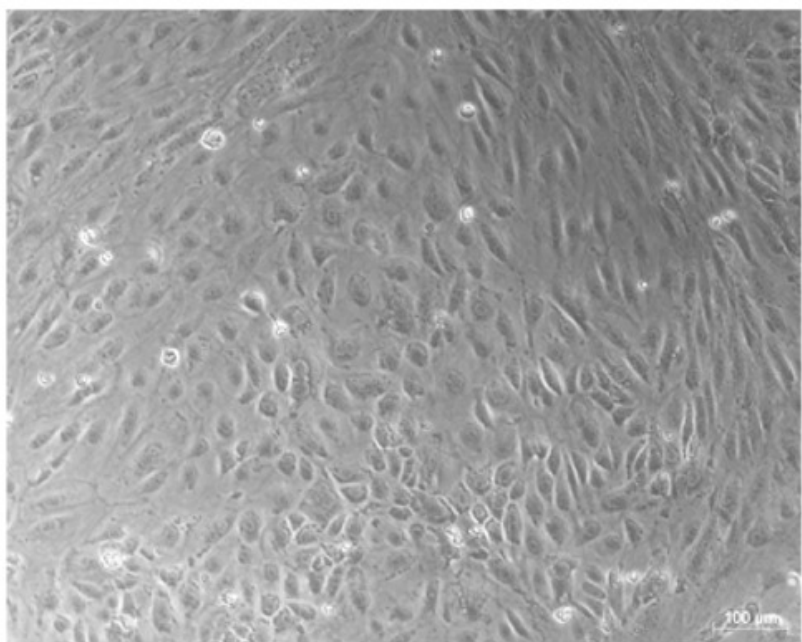

D 


\section{Figure 3}

The phalloidin staining of the undifferentiated $\mathrm{H} 1$ cells and the differentiated $\mathrm{H} 1$ cells.

A, B and C: the undifferentiated cells; D, E and F: the differentiated cells on Day 3; G: a bar graph showing the differences of the average cross sectional area of cells; the experiments were repeated three times; bar:50 $\mu \mathrm{m}$

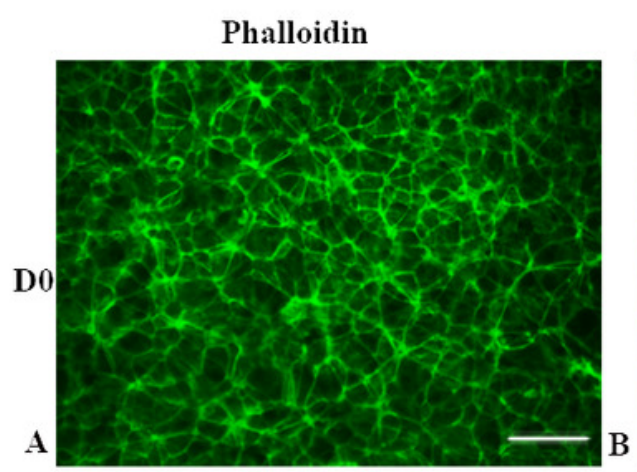

DAPI
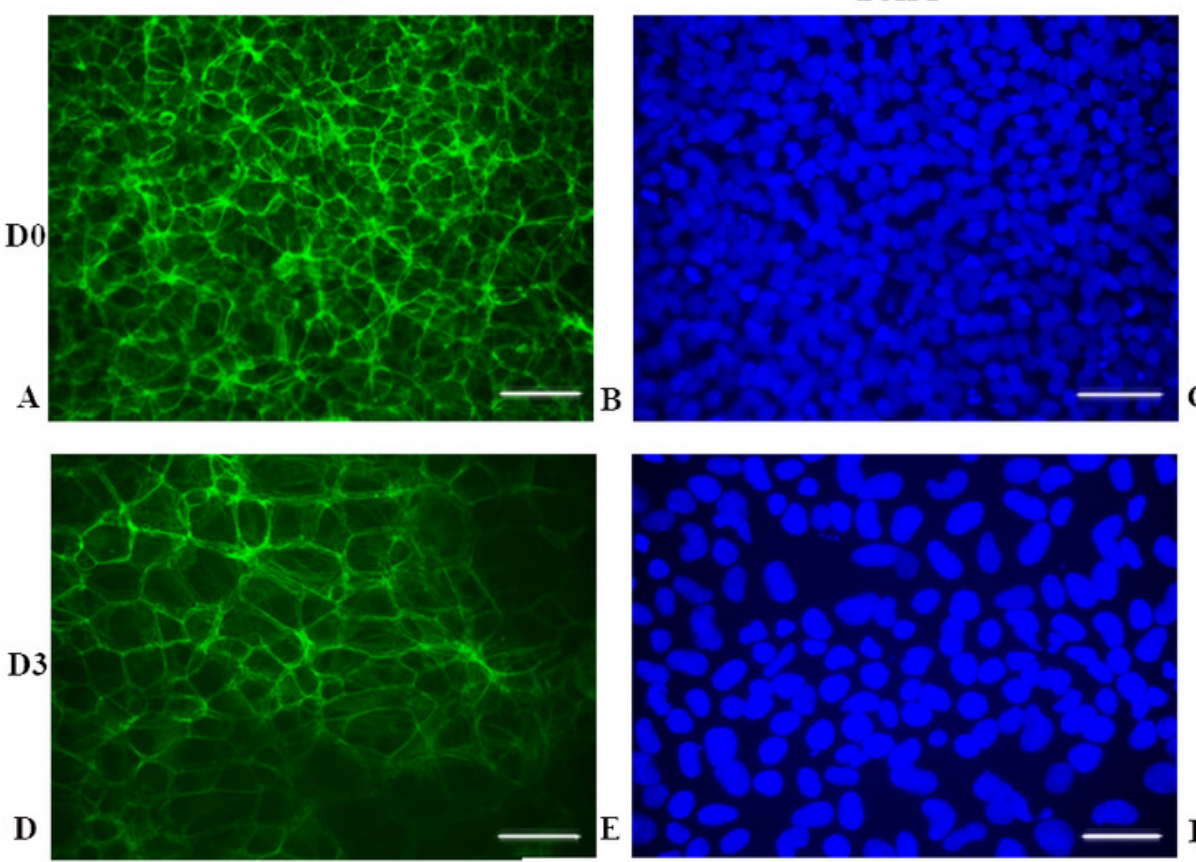
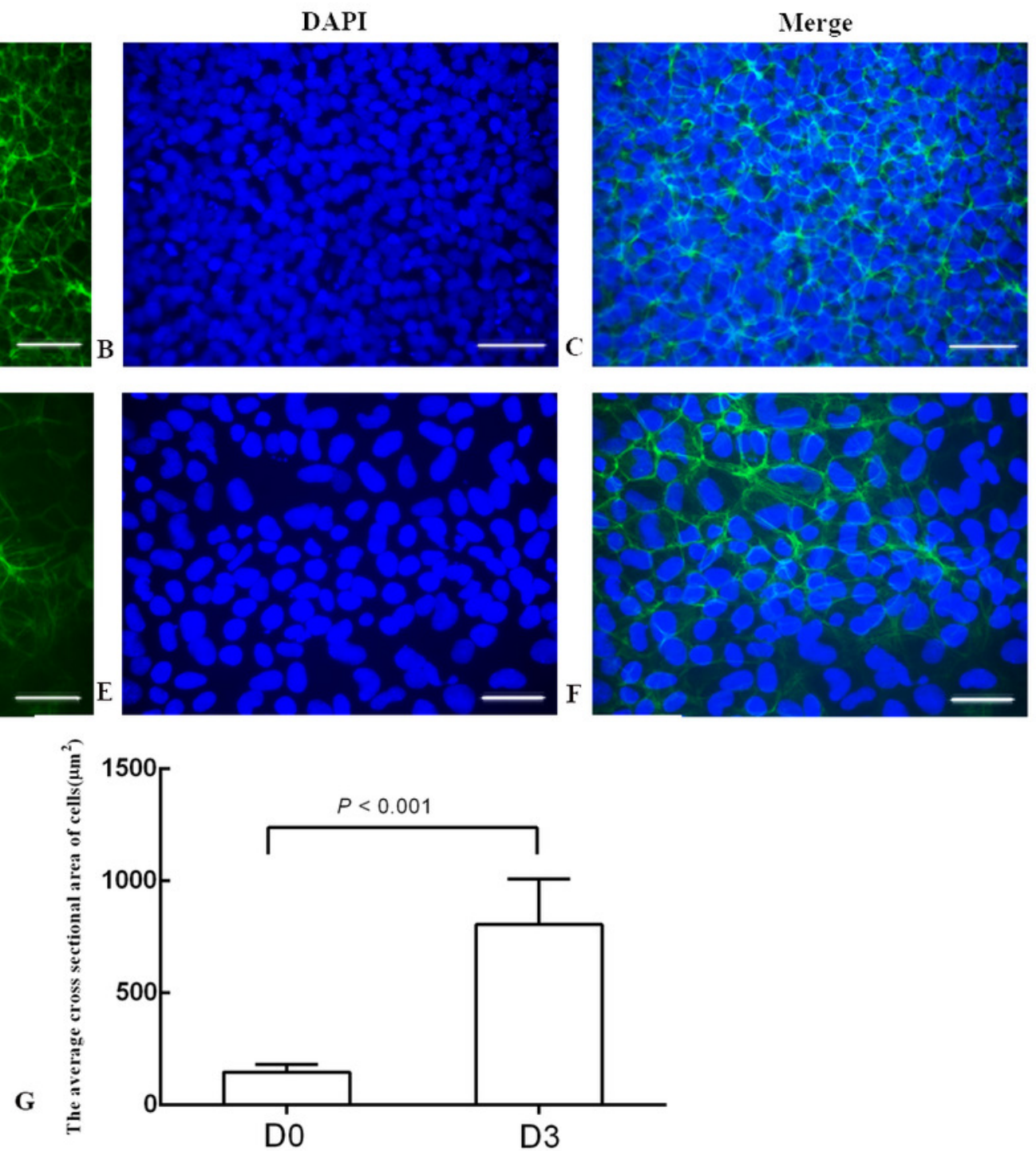


\section{Figure 4}

The expressions of NANOG, CDX2 and $\beta$-hCG mRNA in the undifferentiated $\mathrm{H} 1$ cells and the differentiated $\mathrm{H} 1$ cells on Days 1, 3, 5 and 7

$A$ : the relative expression of NANOG mRNA; $B$ : the relative expression of CDX2 mRNA; $C$ : the relative expression of $\beta$-hCG mRNA; *indicates that compared with the undifferentiated $\mathrm{H} 1$ cells, the differences were statistically significant, $p<0.05 ; n=4$ for each group; $C D X 2=$ caudal type homeobox $2, \beta$-hCG $=\beta$-human chorionic gonadotropin 

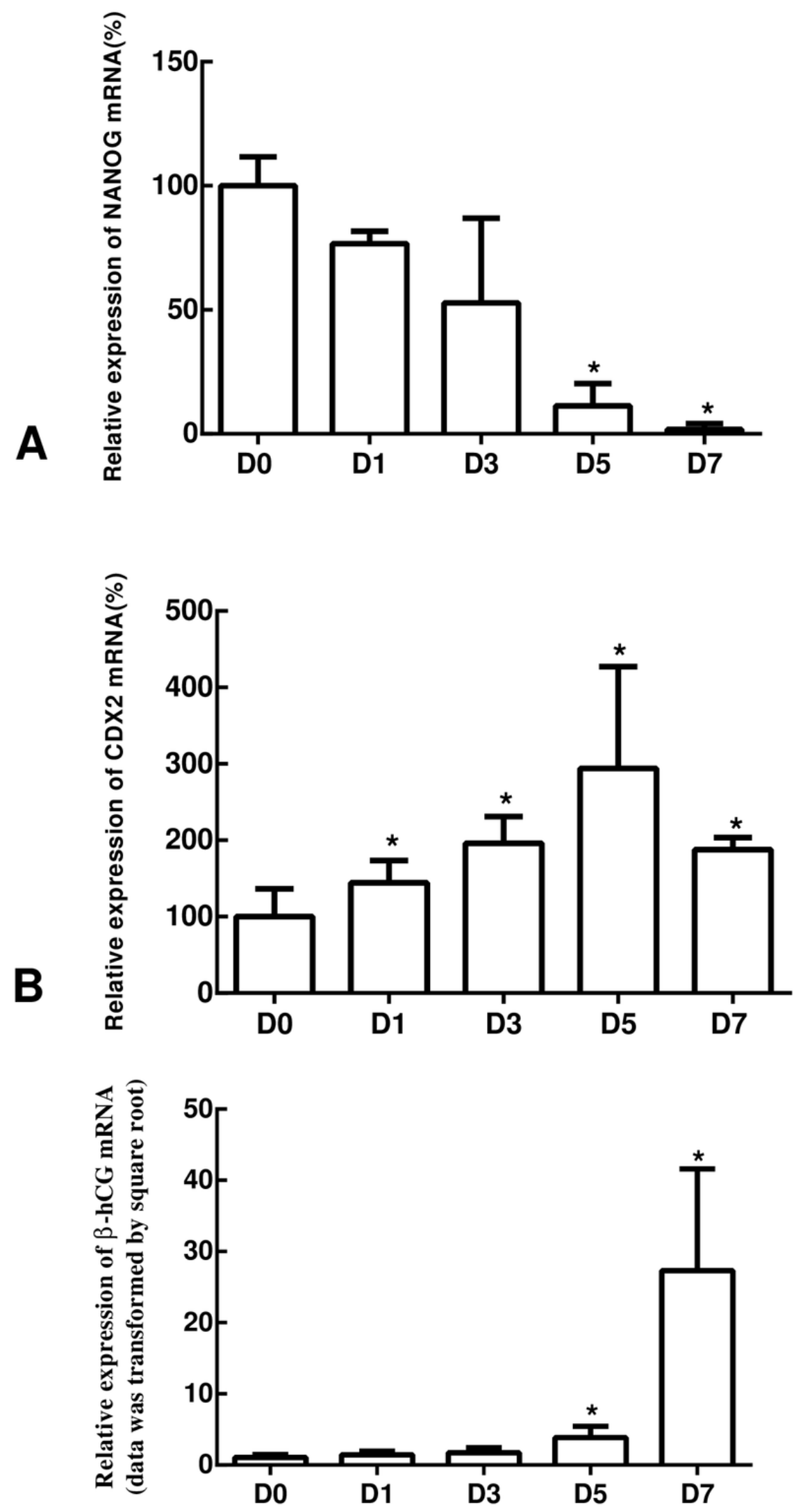

C 
Figure 5

The expressions of mRNA and the copy numbers of syncytin- 1 and syncytin- 2 in the undifferentiated $\mathrm{H} 1$ cells and the differentiated $\mathrm{H} 1$ cells on Days $1,3,5$ and 7

$A$ : the relative expression of syncytin- 1 mRNA; $B$ : the relative expression of syncytin-2 mRNA;

C: the copy number of syncytin-1; D: the copy number of syncytin-2; *indicates that compared with the undifferentiated $\mathrm{H} 1$ cells, the differences were statistically significant, $p<0.05 ; \mathrm{n}=4$ for each group

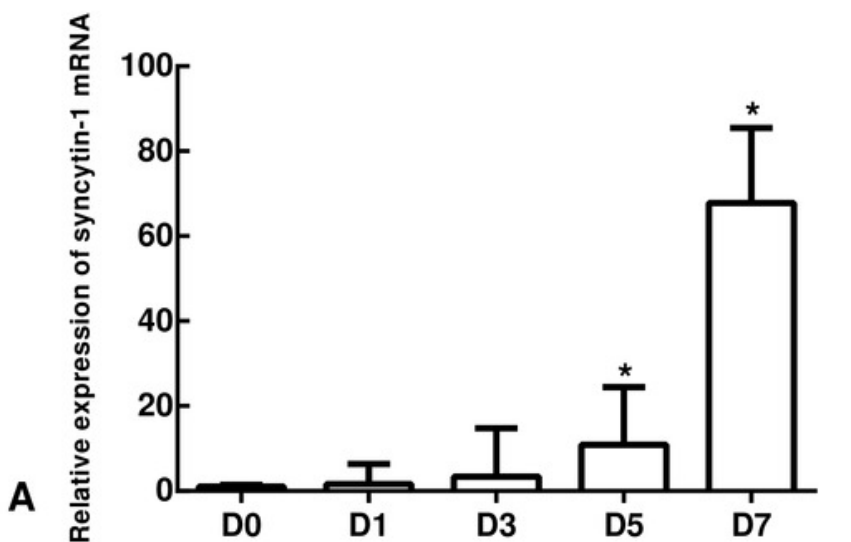

B

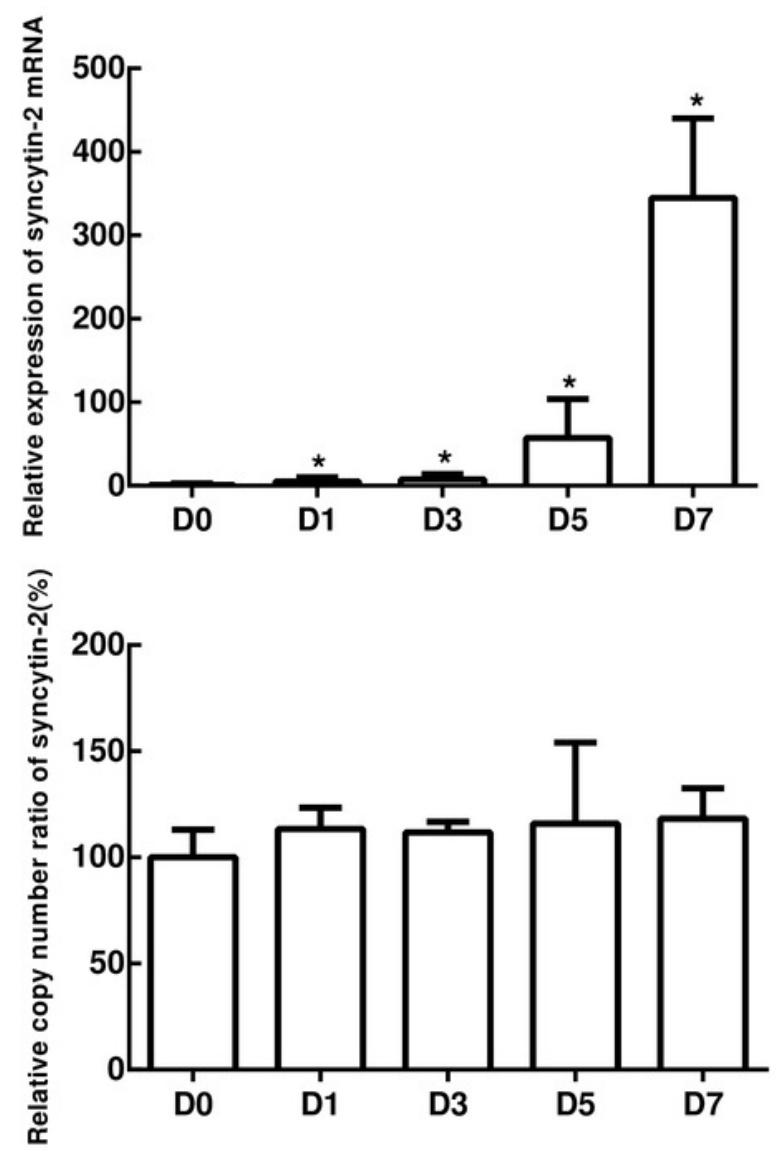




\section{Table $\mathbf{1}$ (on next page)}

The primers for the syncytin-1, syncytin-2 and GAPDH used for the quantitative realtime PCR of genome DNA. 
1 Table 1. The primers for the syncytin-1, syncytin-2 and GAPDH used for the 2 quantitative real-time PCR of genome DNA.

\begin{tabular}{ll}
\hline Gene & Primers \\
\hline Syncytin-1 & 5'-atcataaatccccatggccctc-3'(forward) \\
& 5'-gacgctgcattctccatagaaac-3'(reverse) \\
syncytin-2 & 5'-cggatgtcccttgatatttatacttgt-3' (forward) \\
& 5'-ctgacagagctaaggttctgattagtgt-3'(reverse) \\
GAPDH & 5'-ctgatgccccatgttcgtc-3'(forward) \\
& 5'-caggggtgct aagcagttgg-3'(reverse) \\
\hline
\end{tabular}

3 


\section{Table 2 (on next page)}

The primers of the NANOG, CDX2, HCG, syncytin-1, syncytin-2 and GAPDH used for the quantitative real-time PCR of $\mathrm{mRNA}$ 
1 Table 2. The primers of the NANOG, CDX2, hCG, syncytin-1, syncytin-2 and GAPDH 2 used for the quantitative real-time PCR of mRNA

\begin{tabular}{ll}
\hline Gene & The sequences of primers \\
\hline NANOG & 5'-aactctccaacatcctgaacctc-3' (forward) \\
5'-gtcacaccattgctattcttcgg-3' (reverse) \\
5'aaatccccctagttcccaagac-3'(forward) \\
5'-gcaaagacagagaagagagtgga-3'(reverse) \\
5'-caggactcctcttcctcaaagg-3'(forward) \\
5'-gaagcctttattgtgggaggatc-3'(reverse) \\
5'-cacacaaatagtctgcctaccct-3'(forward) \\
5'-tagatggtcatagggggcactaa-3'(reverse) \\
5'-cagcctcaagatcatcagcaatg-3'(forward) \\
5'-catgccttaaaactcaaggagcc-3'(forward) \\
5yncytin-2
\end{tabular}

3 


\section{Table 3 (on next page)}

The clinical data from patients of pregnant and non-pregnant groups

Note $\square$ values are presented as mean \pm SE or median(interquartile range) or $\%(n)$. 
1

2 Table3. The clinical data from patients of pregnant and non-pregnant groups

3

Peer] reviewing PDF | (2020:05:48792:1:1:NEW 23 Sep 2020) 


\begin{tabular}{|c|c|c|c|}
\hline & $\begin{array}{l}\text { Pregnancy } \\
\text { group(n=32 } \\
\text { embryos) }\end{array}$ & $\begin{array}{l}\text { Non-pregnancy } \\
\text { group ( } n=29 \\
\text { embryos) }\end{array}$ & $p$-value \\
\hline $\operatorname{Age}(\mathrm{y})$ & $31.3 \pm 3.9$ & $31.4 \pm 4.1$ & 0.929 \\
\hline $\mathrm{BMI}\left(\mathrm{kg} / \mathrm{m}^{2}\right)$ & $21.0 \pm 2.4$ & $20.7 \pm 2.0$ & 0.698 \\
\hline Primary infertility(\%) & $25.0 \%(8 / 32)$ & $22.2 \%(4 / 18)$ & 0.825 \\
\hline oligo-astheno-terato- & $46.9 \%(15 / 32)$ & $50.0 \%(9 / 18)$ & 0.832 \\
\hline \multicolumn{4}{|l|}{ Spermia(\%) } \\
\hline Basic FSH & $5.2 \pm 1.0$ & $5.4 \pm 1.1$ & 0.614 \\
\hline Good blastocyst(\%) & $96.9 \%(31)$ & $82.8 \%(24)$ & 0.156 \\
\hline $\begin{array}{l}\text { Thickness of } \\
\text { endometrium (mm) }\end{array}$ & $9.0 \pm 1.1$ & $8.4 \pm 1.6$ & 0.109 \\
\hline Estrogen (pg/ml) & 143.5(116.0-204.8) & $129(95.5-167)$ & 0.278 \\
\hline Progestin (ng/ml) & $12.3(8.5-16.4)$ & $12.3(7.8-16.2)$ & 0.681 \\
\hline $\begin{array}{l}\text { Biochemical } \\
\text { pregnancy }\end{array}$ & 0 & NA & NA \\
\hline Singleton live birth(\%) & $93.75 \%(30)$ & NA & NA \\
\hline Early miscarriage(\%) & $6.25 \%(2)$ & NA & NA \\
\hline
\end{tabular}

